\title{
PENGARUH PENDAPATAN ASLI DAERAH TERHADAP BELANJA MODAL PADA KABUPATEN DAN KOTA PROPINSI SULAWESI UTARA
}

\author{
Oleh : \\ Justonly Lengkong \\ David P.E. Saerang \\ Stanly Alexander \\ Fakultas Ekonomi dan Bisnis, Jurusan Akuntansi \\ Universitas Sam Ratulangi Manado \\ email : Punk_c07@yahoo.com
}

\begin{abstract}
ABSTRAK
Pendapatan Asli Daerah (PAD) merupakan sumber pendapatan utama dari wilayah daerah itu sendiri. PAD diharapkan mampu menunjang Belanja Modal (BM),karena PAD yang meningkat diharapkan akan menambah pendapatan daerah dari pembangunan infrastuktur yang ada. Penelitian ini bertujuan untuk mengetahui pengaruh PAD terhadap BM. Variabel yang digunakan dalam penelitian ini adalah PAD dan BM. Data penelitian berupa data kuantitatif dan merupakan data sekunder yang diperoleh dari Badan Pusat Statistik di Sulawesi Utara. Penelitian ini menggunakan metode regresi sederhana yang dibantu oleh uji asumsi klasik. Hal inimenunjukkan bahwa PAD tidak berpengaruh terhadap BM. Hasil penelitian ini menunjukkan PAD ternyata belum mampu untuk menunjang Belanja Modal karena masih terlalu minim penerimaan daerah. Saran penelitian ini pemerintah diharapkan lebih memperhatikan dan mengembangkan lagi potensi dari wilayah Sulawesi Utara untuk dapat memaksimalkan pendapatan dari daerah.
\end{abstract}

Kata kunci: pendapatan asli daerah dan belanja modal

\begin{abstract}
Regional Original Income is the main source of income of the local region itself. Regional Original Income is expected to be able to support Expense of Capital, because the Regional Original Income will increase is expected to add more revenue from existing infrasturcture development. This research aimed to determine the effect of Regional Original Income for Expense of Capital. Variables used in this research Is the Regional Original Income and Expense of Capital. The research data in the form of quantitative data and a secondary data obtained from the Central Board of Statistic in North Sulawesi. In this research has used simple regression method assisted by classical assumption. This research showed that the Regional Original Income has no effect on Expense of Capital.
\end{abstract}

Keywords : regional original income and expense of capital 


\section{Latar Belakang}

\section{PENDAHULUAN}

Otonomi daerah dalam UU No.32 thn 2004 menjelaskan tentang otonomi daerah adalah hak, wewenang dan kewajiban dalam mengurus sendiri urusan pemerintah dan kepentingan masyarakat setempat sesuai dengan peraturan perundang-undangan.Otonomi daerah memberikan kewenangan yang luas, oleh karena itu otonomi yang berwawasan pembangunan untuk kesejahteraan masyarakat, perlu adanya pemahaman akan kebutuhan yang menjadi landasan berpikir pada bagian mengoperasikan otonomi tersebut sehingga mencapai sasaran untuk meningkatkan taraf dan kualitas hidup bermasyarakat melalui pembangunan daerah, dimana pembangunan daerah bergantung pada Anggaran Pendapatan dan Belanja Daerah (APBD).

Mardiasmo, (2009:73)mengungkapkan bahwa dengan anggaran, pemerintah dapat mengalokasikan sumber daya yang langkah untuk menggerakan pembangunan sosial ekonomi, menjamin kesinambungan dan meningkatkan kualitas hidup bermasyarakat. Melalui pendapatan daerah juga, sumber-sumber penerimaan daerah yang potensial harus digali secara maksimal didalam koridor peraturan perundang-undangan yang berlaku, termasuk diantaranya adalah pajak daerah dan retribusi daerah yang sudah sejak lama menjadi salah satu unsur Pendapatan Asli Daerah (PAD). Digabungkannyaanggaran dengan sumber-sumber pendapatan daerah maka pelaksanaan otonomi daerah bisa memaksimalkan akan kebutuhan dan meningkatkan akan kesejahteraan dari masyarakat daerah.

Pemberian otonomi daerah berpengaruh terhadap tingkat pertumbuhan ekonomi suatu daerah karena memberikan kebebasan kepada pemerintah daerah untuk membuat rencana keuangannya sendiri dan membuat kebijakan-kebijakan yang dapat berpengaruh pada kemajuan daerahnya. Peran pemerintah didalam pembangunan adalah sebagai katalisator dan fasilitator, karena pihak pemerintahlah yang lebih mengetahui sasaran tujuan pembangunan yang akan dicapai(Abdul dan Halim, 2004:237). Dalam rangka menjalankan fungsi dan kewenangan pemerintah daerah dalam bentuk pelaksanaan kewenangan fiskal, setiap daerah harus dapat mengenali potensi dan mengidentifikasi sumber-sumber daya yang dimilikinya, khususnya untuk memenuhi kebutuhan pembiayaan pemerintah dan pembangunan didaerahnya melalui PAD.PAD merupakan hal yang penting untuk menentukan tingkat kemampuan daerah dalam melaksanakan otonomi daerah secara nyata dan bertanggung jawab.

Upaya pemerintah dalam meningkatkan PAD tidak akan memberikan arti apabila tidak diikuti dengan peningkatan pertumbuhan ekonomi daerah tersebut. Dilain pihak, pemerintah daerah juga bertanggung jawab penuh terhadap pengelolaan keuangan yang berasal dari PAD tersebut, karena dana itu berasal dari masyarakat daerah setempat yang berhak untuk mendapatkan kembali dana tersebut dalam bentuk pembangunan yang dilaksanakan pada daerahnya. Karena itu dalam menjalani otonomi daerah yang sukses tergantung pada pimpinan-pimpinan daerah atau Pemerintah Daerah (Pemda) yang memotorisasi dengan baik demi kesejahtraan masyarakat dan peningkatan dalam hal ekonomi daerah tersebut.

Setiap daerah saat ini seolah-olah berlomba untuk meningkatkan pembangunan daerahnya sendiri, dan salah satu faktor pendukung kesejahteraan daerah adalah dengan tersedianya infrasruktur yang memadai. Peran PAD dalam meningkatkan kesejahteraan pada daerahnya sendiri adalah dengan meningkatkan investasi Belanja Modal (BM) pada pemerintah daerah sehingga kualitas layanan publik daerah semakin baik.Seiring meningkatnya investasi BM, pemerintah mendorong daerah untuk melakukan pembangunan ekonomi dengan mengelola sumber daya yang ada dan membentuk suatu kemitraan pada masyarakat demi mencapai kesejahteraan bagi masyarakat dengan membangun lapangan kerja yang baru dan mencapai tingkat PAD yang membaik atau meningkat.

Sembiring, (2009:13) mengungkapkan bahwa dalam konteks pengelolaan keuangan daerah, BM sangat berkaitan dengan perencanaan keuangan jangka panjang, terutama pembiayaan untuk pemeliharaan aset tetap yang dihasilkan dari BM tersebut. Pemerintah harus beradaptasi untuk mengupayakan mutu pelayanan publik dan perbaikan berbagai sektor yang berpotensi agar mengubah struktur belanja semakin baik. Pemerintah juga harus memberikan proporsi BM yang lebih besar, pergeseran komposisi belanja merupakan upaya logis yang dilakukan pemerintah daerah setempat dalam rangka meningkatkan tingkat kepercayaan publik, pergeseran ini ditujukan untuk meningkatkan investasi BM. Peningkatan alokasi BM dalam bentuk aset tetap seperti infrastruktur memang sangat penting untuk meningkatkan produktivitsa perekonomian, dan diharapkan akan bertambahnya pendapatan daerah.

Solikin, (2007:7) menyatakan bahwa semakin tinggi PAD maka pengeluaran pemerintah atas BM pun akan semakin tinggi, artinya temuan tersebut mengindikasikan bahwa besarnya PAD menjadi salah satu faktor penentu dalam menentukan BM. Penelitian ini mengacu pada penelitian yang dilakukan oleh Sembiring, (2009) dan Solikin, (2007) tentang PAD yang berpengaruh terhadap BM. 


\section{Pengertian Otonomi Daerah}

\section{TINJAUAN PUSTAKA}

Undang-Undang No. 32 tahun 2004 pasal 1 ayat 5 tentang Pemerintah Daerah menyebutkan bahwaotonomi derah adalah hak, wewenang dan kewajiban daerah otonom untuk mengatur dan mengurus sendiri urusan pemerintah dan kepentingan masyarakat setempat sesuai dengan peraturan perundangundangan(www.sarjanaku.com, 2012). Suparmoko (2002:61) dalam www.sarjanaku.com (2012) mengartikan otonomi daerah adalah kewenangan daerah otonom untuk mengatur dan mengurus kepentingan masyarakat setempat menurut prakarsa sendiri berdasarkan aspirasi masyarakat.

\section{Anggaran Pendapatan dan Belanja Daerah (APBD)}

Salah satu sumber keuangan untuk penyelenggaraan pembangunan adalah pendapatan daerah. Pemerintah Daerah (Pemda) menyusun dan menetapkan (APBD) adalah sebagai alat utama untuk menjalankan otonomi daerah yang nyata dan bertanggung jawab, dan merupakan rencana operasional keuangan daerah yang menggambarkan pengeluaran untuk kegiatan keseharian dan proyek pembangunan daerah dalam satu anggaran tertentu dan sumber penerimaan daerah dari hasil pajak daerah, retribusi pajak daerah, hasil perusahaan daerah dan hasil usaha lain yang sah untuk menutupi pengeluaran tersebut.

\section{Pendapatan Asli Daerah (PAD)}

Halim (2009:62) menyatakan bahwa PAD adalah penerimaan daerah yang diperoleh dari sumbersumber ddalam wilayahnya sendiri yang dipungut berdasarkan peraturan daerah sesuai dengan peraturan perundang-undangan yang berlaku. Mardiasmo (2009:132) menyatakan bahwa Pendapatan Asli Daerah adalah penerimaan yang diperoleh dari sektor pajak daerah, retribusi daerah, hasil perusahaan milik daerah, hasil pengelolaan kekayaan daerah yang dipisahkan dan lain-lain pendapatan yang sah.

PAD adalah pendapatan yang diperoleh daerah yang dipungut berdasarkan peraturan daerah yang sesuai dengan UU No. 33 tahun 2004, pasal 1 tentang Perimbangan Keuangan antara Pemerintah Pusat dan Pemerintah Daerahyang menyatakan bahwa untuk mengumpulkan dana, guna keperluan daerah yang bersangkutan dalam membiayai kegiatannya. PAD bersumber dari :

1. Pajak Daerah

2. Retribusi Daerah

3.Hasil Pengelolaan Kekayaan Daerah Yang Dipisahkan

4. Lain-lain Pendapatan Asli Daerah Yang Sah

\section{Belanja Modal (BM)}

BM adalah pengeluaran yang digunakan untuk pembelian/pengadaan atau pembangunan aset tetap berwujud yang nilai manfaatnya lebih dari setahun atau pemakaian jasa dalam melaksanakan program dan kegiatan pemerintah daerah. Belanja Modal dapat dikategorikan dalam 5 kategori yaitu :

1. Belanja Modal Tanah

2. Belanja Modal Peralatan dan Mesin

3. Belanja Modal Gedung dan Bangunan

4. Belanja Modal Jalan, Irigasi dan Jaringan

5. Belanja Modal Fisik Lainnya 
Penelitian Terdahulu

Tabel 1. Penelitian Terdahulu

\begin{tabular}{|c|c|c|c|c|c|}
\hline Nama/Tahun & Judul & Variabel & Hasil & Persamaan & Perbedaan \\
\hline Solikin (2007) & $\begin{array}{l}\text { Hubungan Pendapatan } \\
\text { Asli Daerah dan Dana } \\
\text { Alokasi Umum dengan } \\
\text { Belanja Modal di Jawa } \\
\text { Barat }\end{array}$ & $\begin{array}{l}\text { Dana Alokasi } \\
\text { Umum } \\
\text { Belanja Modal }\end{array}$ & 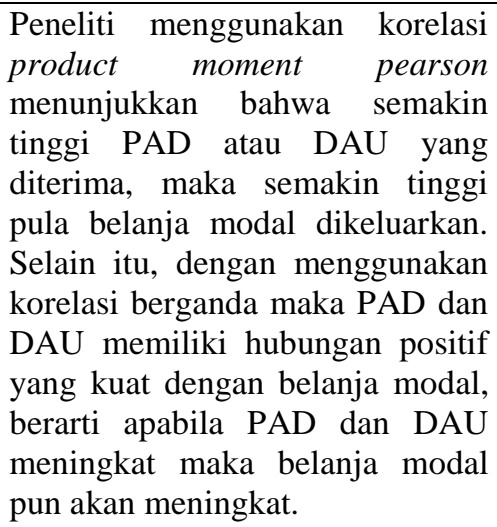 & $\begin{array}{l}\text { Peneliti } \\
\text { sebelumnya } \\
\text { melakukan } \\
\text { penelitian } \\
\text { tentang } \\
\text { pengaruh } \\
\text { PAD } \\
\text { terhadap BM }\end{array}$ & $\begin{array}{l}\text { Penelitian } \\
\text { yang } \\
\text { dilakukan } \\
\text { bertempat } \\
\text { pada } \\
\text { kabupaten dan } \\
\text { kota se Jawa } \\
\text { Barat. }\end{array}$ \\
\hline Putro (2010) & $\begin{array}{l}\text { Pengaruh Pertumbuhan } \\
\text { Ekonomi, Pendapatan } \\
\text { Asli Daerah dan Dana } \\
\text { Alokasi r Umum } \\
\text { terhadap Pengalokasian } \\
\text { Anggaran } \\
\text { Modal }\end{array}$ & $\begin{array}{l}\text { Pertumbuhan } \\
\text { Ekonomi } \\
\text { Pendapatan } \\
\text { Asli Daerah } \\
\text { Dana Alokasi } \\
\text { Umum } \\
\text { Belanja Modal }\end{array}$ & $\begin{array}{l}\text { Hasil pengujian menunjukkan } \\
\text { bahwa hanya DAU yang } \\
\text { berpengaruh signifikan terhadap } \\
\text { pengalokasian anggaran belanja } \\
\text { modal sedangkan Pertumbuhan } \\
\text { Ekonomi dan PAD tidak } \\
\text { berpengaruh signifikan terhadap } \\
\text { pengalokasian anggaran belanja } \\
\text { modal. }\end{array}$ & $\begin{array}{l}\text { Peneliti } \\
\text { sebelumnya } \\
\text { melakukan } \\
\text { penelitian } \\
\text { terhadap } \\
\text { pengaruh } \\
\text { PAD pada } \\
\text { BM }\end{array}$ & $\begin{array}{l}\text { Peneliti } \\
\text { melakukan } \\
\text { penelitian } \\
\text { pengaruh PAD } \\
\text { terhadap } \\
\text { pengalokasian } \\
\text { anggaran BM } \\
\text { di Propinsi } \\
\text { Jawa Tengah }\end{array}$ \\
\hline
\end{tabular}

Sumber : Hasil Penelitian, 2013

\section{Hubungan PAD dengan Belanja Modal}

Mardiasmo, (2009:46) menyatakan bahwa selama ini PAD memiliki peran untuk pelaksanaan otonomi daerah guna mencapai tujuan utama penyelengaraan otonomi daerah yang ingin meningkatkan pelayanan publik dan memajukan perekonomian daerah. Bermula dari keinginan untuk mewujudkan harapan tersebut, pemda melakukan berbagai cara dalam meningkatkan pelayanan publik, yang salah satunya dilakukan dengan belanja untuk kepentingan investasi yang direalisasikan melalui belanja modal(Solikin, 2007).

PAD sebenarnya merupakan andalan utama daerah untuk mendukung penyelenggaraan pemerintah dan pembiayaan pembangunan (Solikin, dikutip dalam Saragih, 2003:49). Tetapi penerimaan daerah dari unsur PAD saja belum mampu memenuhi kebutuhan daerah apalagi dengan penambahan wewenang daerah jelas akan membutuhkan dana tambahan bagi daerah (Solikin, dikutip dalam Saragih, 2003:49) sehingga daerah masih membutuhkan bantuan dana yang lain misalnya Dana Alokasi Khusus, Dana Alokasi Umum dan faktor-faktor lain yang dapat memenuhi kebutuhan daerah.

\section{Jenis Penelitian}

\section{METODE PENELITIAN}

Penelitian yang digunakan adalah metode Asosiasi. Jenis penelitian ini digunakan karena menurut (Sugiyono, 2003:33), penelitian asosiatif merupakan penelitian yang bertujuan untuk mengetahui pengaruh ataupun juga hubungan antar dua variabel atau lebih. Variabel yang digunakan dalam penelitian ini adalah PAD, PADdalam hal ini adalahpendapatan daerah kabupaten dan kota yang bersumber dari hasil pajak daerah (HPD), hasil retribusi daerah (HRD), hasil perusahaan milik daerah serta hasil pengolahan kekayaan daerah (HPKD) dan lain-lain pendapatan yang sah (LPS). Variabel ini di ukur dengan satuan Rupiah dan jugadiposisikan sebagai variabel independen dan variabel brikutnya adalahBM, BMdalam penelitian ini diartikan sebagai pengeluaran yang dilakukan dalam rangka menambah aset atau kekayaan daerah kabupaten dan kota yang masa manfaatnya lebih dari satu tahun anggaran, yang meliputi antara lain belanja untuk perolehan tanah, peralatan dan mesin, gedung dan bangunan, belanja jalan, irigasi dan jaringan dan juga belanja aset lainnya. Variabel ini di ukur dengan satuan Rupiah dan juga diposisikan sebagai variabel dependen. 


\section{Metode Pengumpulan Data}

Pengumpulan data melalui bahan tertulis berupa buku-buku, data-data yang tersedia dan laporanlaporan yang relevan dengan objek penelitian (Dokumentasi). Adapun sampel dalam penelitian ini adalah 15 (seluruh) Kabupaten dan Kota di Propinsi Sulaweisi Utara.

\section{Metode Analisis}

Analisis data yang digunakan dalam penelitian ini adalah dengan menggunakan model regresi sederhana melalui persamaan sebagai berikut:

$$
\mathrm{Y}=\alpha+\mathrm{bX}
$$

Keterangan :

$\mathrm{Y} \quad=$ Variabel dependen (nilai yang diprediksi)

$\mathrm{X}=$ Variabel independen

$\alpha=$ Konstanta

$\mathrm{b} \quad=$ Koefisien Regresi (nilai peningkatan ataupun penurunan)

\section{Hasil Penelitian}

\section{HASIL PENELITIAN DAN PEMBAHASAN}

Tabel 2. Standar Deviasi

\begin{tabular}{|c|c|c|c|c|c|}
\hline Variabel & $\mathbf{N}$ & Minimum & Maximum & Mean & Std.Deviation \\
\hline Pendapatan Asli Daerah & 45 & 414.798 & 134.721 .720 & $18.833 .196,93$ & $27.389 .407,24$ \\
\hline Belanja Modal & 45 & 5.948 .027 & 178.968 .83 & $105.702 .437,1$ & $44.840 .070,83$ \\
\hline Valid N(listwise) & 45 & & & & \\
\hline
\end{tabular}

Sumber : Data olah, 2013 berikut :

Tabel 2 diatas menjelaskan tentang populasi sebanyak 45 data dan memperoleh data deskripsi sebagai

1. Pendapatan Asli Daerah maksimum yang dimiliki oleh Propinsi Sulawesi Utara Rp.134.721.720 ribu, minimum Rp.424.798 ribu, dan rata-rata adalah Rp.18.833.916,93 ribu dengan standar deviasi Rp.27.389.407,24 ribu.

2. Belanja Modal maksimum yang dimiliki oleh Propinsi Sulawesi Utara adalah Rp.178.968.835 ribu, minimum Rp. 5.948.027 ribu dan rata-rata Rp. 105.702.437,18 ribu dengan standar deviasi Rp. 44.840.070,83 
Tabel 3. Jumlah Pendapatan Asli Daerah dan Belanja Modal menurut BPS tahun 2009-2011

\begin{tabular}{|c|c|c|c|}
\hline Kabupaten dan Kota & Tahun & $\begin{array}{l}\text { Pendapatan Asli } \\
\text { Daerah }\end{array}$ & Belanja Modal \\
\hline Bolaang Mongondow & 2009 & 79.870 .10 & 138.045 .907 \\
\hline Minahasa & 2009 & 23.746 .219 & 153.960 .182 \\
\hline Kep. Sangihe Talaud & 2009 & 33.076 .684 & 161.273 .533 \\
\hline Kep. Talaud & 2009 & 5.152 .506 & 78.506 .962 \\
\hline Minahasa Selatan & 2009 & 6.598 .234 & 92.252 .916 \\
\hline Minahasa Utara & 2009 & 11.755 .840 & 39.984 .975 \\
\hline Bolmong Utara & 2009 & 4.366 .699 & 147.114 .182 \\
\hline Sitaro & 2009 & 8.477 .802 & 126.143 .361 \\
\hline Mitra & 2009 & 2.705 .000 & 161.808 .201 \\
\hline Bolmong Selatan & 2009 & 858.691 & 22.224 .894 \\
\hline Bolmong Timur & 2009 & 414.798 & 14.594 .928 \\
\hline Manado & 2009 & 72.404 .996 & 60.648 .654 \\
\hline Bitung & 2009 & 16.822 .774 & 96.790 .462 \\
\hline Tomohon & 2009 & 14.991 .099 & 138.226 .282 \\
\hline Kotamobagu & 2009 & 6.142 .246 & 131.972 .797 \\
\hline Bolaang Mongondow & 2010 & 98.494 .245 & 5.948 .027 \\
\hline Minahasa & 2010 & 24.660 .934 & 72.584 .187 \\
\hline Kep. Sangihe Talaud & 2010 & 23.768 .306 & 122.420 .734 \\
\hline Kep. Talaud & 2010 & 7.704 .136 & 79.881 .090 \\
\hline Minahasa Selatan & 2010 & 5.594 .269 & 31.979 .532 \\
\hline Minahasa Utara & 2010 & 10.982 .002 & 72.584 .187 \\
\hline Bolmong Utara & 2010 & 9.090 .042 & 160.088 .367 \\
\hline Sitaro & 2010 & 12.027 .487 & 148.049 .899 \\
\hline Mitra & 2010 & 4.430 .162 & 79.524 .066 \\
\hline Bolmong Selatan & 2010 & 2.376 .960 & 103.601 .273 \\
\hline Bolmong Timur & 2010 & 2.871 .281 & 115.593 .388 \\
\hline Manado & 2010 & 90.828 .484 & 97.490 .453 \\
\hline Bitung & 2010 & 18.763 .528 & 113.573 .131 \\
\hline Tomohon & 2010 & 5.713 .312 & 59.235 .695 \\
\hline Kotamobagu & 2010 & 8.957 .374 & 149.644 .788 \\
\hline Bolaang Mongondow & 2011 & 5.535 .929 & 83.860 .407 \\
\hline Minahasa & 2011 & 23.809 .005 & 97.987 .506 \\
\hline Kep. Sangihe Talaud & 2011 & 28.506 .001 & 95.738 .052 \\
\hline Kep. Talaud & 2011 & 8.735 .988 & 62.651 .657 \\
\hline Minahasa Selatan & 2011 & 9.407 .000 & 84.390 .000 \\
\hline Minahasa Utara & 2011 & 15.720 .000 & 96.971 .000 \\
\hline Bolmong Utara & 2011 & 7.318 .745 & 178.968 .835 \\
\hline Sitaro & 2011 & 13.703 .246 & 177.258 .164 \\
\hline Mitra & 2011 & 4.956 .000 & 140.499 .000 \\
\hline Bolmong Selatan & 2011 & 5.481 .338 & 130.030 .217 \\
\hline Bolmong Timur & 2011 & 4.992 .038 & 170.553 .681 \\
\hline Manado & 2011 & 134.721 .720 & 165.582 .485 \\
\hline Bitung & 2011 & 25.394 .063 & 103.257 .610 \\
\hline Tomohon & 2011 & 8.095 .030 & 76.564 .107 \\
\hline Kotamobagu & 2011 & 9.354 .639 & 116.549 .899 \\
\hline \multicolumn{2}{|c|}{ Jumlah } & 847.493 .862 & 4. 756.609 .673 \\
\hline
\end{tabular}

Sumber : Badan Pusat Statistik Sulawesi Utara, 2013

Jumlah keseluruhan PAD tahun 2009-2011 adalah Rp.847.493.862 dan BM dari tahun 2009-2011 adalah 4.756.609.673. Terlihat dari jumlah keseluruhan bahwa biaya pengeluaran BMjauh lebih meningkat dibandingkan PAD 


\section{Pembahasan}

Pengujian hipotesis dalam penelitian ini menggunakan uji regresi sederhana dan hasilnya sebagai berikut:

Tabel 4. Hasil Uji Regresi

\begin{tabular}{|l|l|l|l|}
\hline Variabel & Beta & t hitung & Sig \\
\hline $\begin{array}{l}\text { Pendapatan Asli } \\
\text { Daerah }\end{array}$ & $-0,029$ & $-0,175$ & 0,862 \\
\hline
\end{tabular}

Sumber : Data sekunder yang diolah, 2013

Hasil pengujian Hipotesis menyatakan PAD tidak berpengaruh terhadap BM dengan nilai t sebesar 0,175 dengan signifikan 0,862. Nilai pengujian tersebut lebih besar dari 0,05. Dengan demikian maka ditujukan bahwa pada taraf signifikan 5\% PAD secara signifikan tidak berpengaruh terhadap BM. Sehingga dapat dinyatakan bahwa jika nilai variabel PAD meningkat tidak akan berdampak pada meningkatnya nilai dari variabel BM. Hal ini berarti H0 diterima dan Ha ditolak.

Persamaan Regresi ;

$\mathrm{Y}=\alpha+\mathrm{bX}$

$\mathrm{Y}=10081,313+-0,029 \mathrm{X}$

$\mathrm{Y}=10081,313-0,029 \mathrm{X}$

Nilai b yang merupakan koefisien variabel PAD $(X)$ pada persamaan tersebut adalah sebesar minus 0,029 dengan tingkat signifikan 0,862 . Hali ini berarti variabel PAD (X) tidak berpengaruh signifikan pada level signifikan sebesar 5\% terhadap variabel BM (Y). Sehingga dapat dinyatakan bahwa jika nilai variabel PAD (X) meningkat, maka tidak akan berdampak pada nilai dari variabel BM (Y).

\section{Kesimpulan}

\section{PENUTUP}

Hasil penelitian yang telah dilakukan, dapat disimpulkan bahwa PAD tidak berpengaruh terhadap BM yang artinya PAD belum cukup mampu untuk menunjang BM karena terlalu kecil Pendapatan daerahnya. Karena juga untuk BM, pemerintah daerah masih mengharapkan bantuan/transfer dana dari pemerintah Pusat.

\section{Saran}

Penulis memberi saran yaitu pemerintah daerah lebih melihat lagi potensi daerahnya sendiri agar bisa di manfaatkan dan dapat menambah pendapatan daerah agar bisa dapat menunjang BM dalam hal ini pembangunan infrastruktur bangunan dengan harapan dapat meningkatnya pendapatan daerah dari penambahan infrastruktur tersebut.

\section{DAFTAR PUSTAKA}

Abdul., Halim. 2004. Bunga Rampai Manajemen Keuangan Daerah. UPP AMP YKPN. Jogjakarta.

Badan Pusat Statistik (BPS). 2013. Statistik Keuangan Pemerintahan Kabupaten/kota. Jakarta

Halim, Abdul. 2009. Akuntansi Keuangan Daerah Edisi Revisi. Salemba Empat. Jakarta.

Mardiasmo, 2009. Akuntansi Sektor Publik. Andi. Jogjakarta.

Putro, Nugroho Suratno. 2010. Pengaruh Pertumbuhan Ekonomi, Pendapatan Asli Daerah dan Dana Alokasi Umum terhadap Pengalokasian Anggaran Belanja Modal. Skripsi. Fakultas Ekonomi Universitas Diponegoro. Semarang.

Sembiring, Sri Hayati BR. 2009. Analisis Pengaruh Belanja modal dan Pendapatan Asli Daerah terhadap Belanja Pemeliharaan dalam Realisasi Anggaran Pemerintahan Kabupaten dan Kota di Propinsi Sumatra Utara. Skripsi. Universitas Sumatra Utara. Medan.

Solikin, Ikin. 2007. Hubungan Pendapatan Asli Daerah dan Dana Alokasi Umum dengan Belanja Modal di Jawa Barat.Jurnal Eksklusif Vol.4 No.4. Universitas Pendidikan Indonesia Bandung. Slipi. Jakarta.

Suparmoko. 2002. Ekonomi Publik. Andi. Jogjakarta.

Saragih, Juli Panglima. 2003. Desentralisasi Fiskal dan Keuangan Daerah dalam Otonomi. Ghalia Indonesia. Jakarta.

Sugiyono. 2003. Metode Penelitian Bisnis. Pusat Bahasa Depdiknas. Bandung. 
Yasin, Sanjaya. 2012. Pengertian Otonomi Daerah Makalah, Tujuan,. Prinsip, Undang-undang. Jakarta. htttp://sarjanaku.com. diunggah 11 juli 2013.

Republik Indonesia, Peraturan Menteri Dalam Negeri Republik Indonesia No. 32 Tahun 2004 Tentang Pemerintah Daerah. Jakarta.

UU Nomor 33 Tahun 2004 tentang Perimbangan Keuangan Pemerintah Pusat dan Pemerintah Daerah. Jakarta. 